\title{
Impact of IGF-1, GH and Oxidative Stress in the Experimental Model of Juvenile and Adult Hypothyroid Retinal Degeneration
}

\author{
Omyma Galal, Effat Awad, Amal Taha* and Faten Y. Mahmoud** \\ Departments of Physiology, Histology*and Anatomy* *; \\ Faculty of Medicine, Assiut University, Egypt
}

\begin{abstract}
Background: The pathophysiological mechanisms involved in hypothyroid retinal damage are still debate. Materials and methods: To study these mechanisms, ninety six pubs of albino rats were equally divided into three groups, control, hypothyroid model and thyroid supplement. Each group was separated into two juvenile and adult subgroups that were sacrificed at day 20 and 60 postnatally respectively. Pubs in hypothyroid group their mother received $0.05 \mathrm{mg}$ carbimazole/day/pregnant female orally during gestation and 20 days of lactation in juvenile subgroup while adult subgroup received the hypothyroid agent until day 60 postnatally. Thyroid supplement group received antithyroid agent then treated with L-thyroxine (TH) orally (10 ug/ kg body weight) for one month. Results: A significant reduction in body weight, temperature, heart rate, levels of T3, T4, GH, IGF-1, and antioxidant enzymes while increased systolic pressure and LP products were evident in hypothyroid subgroups associated with decreased in the thickness and degeneration of retinal layers. Thyroid supplementation group showed a partial normalization of the measured mediators accompanied with recovery of structural changes especially in juvenile subgroup. Conclusions: Thyroid H has a vital role in normal retinal growth. Also, GH, IGF-1, oxidative stress are significant mediators of retinal degeneration.
\end{abstract}

\section{INTRODUCTION}

The thyroid hormone axis has an important role in the physiological functions and development of CNS, including the eye $^{(\mathbf{1 , 2})}$. Retinal degeneration persists to be a significant cause of blindness worldwide. It is possible that further reductions in the prevalence and severity of blindness caused by retinal degeneration can be made only with advancements in the prevention of its causes, rather than treatment of it once occurs.
Insulin-like growth factor (IGF)-I and growth hormone $(\mathrm{GH})$ are major regulators of normal growth and activity of retina in mice and humans ${ }^{(3,4)}$. Besides, IGF-1 is a critical modulator of thyroid activity. Infants born very prematurely $(<27$ weeks) are more likely to have low thyroxine $\left(T_{4}\right)$ levels, indicating an abnormal hypothalamus-pituitarythyroid axis function ${ }^{(5)}$. These considerations raise the possibility that hypothyroidism may be involved in retinal degeneration. 
Growth factors have been found in vitreous fluid, in which they regulate retinal function and provide markers of ocular degeneration. The presence of $\mathrm{GH}$ in the human retina and vitreous fluid suggests that GH may have roles in visual function and may be involved in the pathophysiological theories of ocular degeneration ${ }^{(6)}$. Free radicals are known to damage cellular components and change the levels of lipid peroxidation and antioxidant enzyme activities in different tissues of hypothyroid rats that mostly cause functional disorder of these tissues ${ }^{(7)}$.

Multiple pathophysiological mechanisms may be involved in explanation of hypothyroid retinal degeneration. However our knowledge about the exact mechanisms is still not clear. We hypothesized that hypothyroidism would induce retinal degeneration and supplementation with thyroxine can ameliorate this condition. The rational behind this research was to focus on the role of IGF-1, GH and oxidative stress as contributors to hypothyroid retinal damage. To test our hypothesis, a hypothyroid animal model (white albino rats) was established. The animals were divided into three equal groups; control, hypothyroid model and thyroid supplement. Each group was separated into juvenile and adult subgroups.

\section{MATERIALS \& METHODS}

During all the experiments, the animals were treated in accordance with the published rules for animal laboratory care, and the protocol has been approved by the Committee of
Assuit University, School of Medicine, Assuit, Egypt.

Animals and maintenance:

A total number of ninety six newly born male rats were used and obtained from Assuit University Animal Facility. They were housed in Animal Facility, Faculty of Medicine, Assuit University, Assuit, Egypt, with room temperature maintained at $65-$ 75 F, relative humidity of $50-70 \%$ and an airflow rate of 15 exchanges $/ \mathrm{h}$. In addition, a time controlled system pro-vided 12:12-h light-dark cycle. All animals were given food and water ad libitum.

Induction of hypothyroid model:

After a 7-day acclimatization period, experimentally native, infection-free, adult female Wisteralbino rats weighing 200-250 grams, were placed in individual wire mesh cages and were mated with adult male rats for copulation. After confirming pregnancies by daily morning examination until finding of vaginal plug, the pregnant rats were placed in nesting cages and remained undisturbed until delivery.

Thirty gravid rats (dams) were then randomly assigned into two groups. One of them was the hypothyroid group $(n=25)$ that just received antithyroid agent carbimazole (Neo-mercazole, Sigma Chemical, Co., St Louis, MO,) 0.05 $\mathrm{mg} / \mathrm{kg}$ body weight, orally by gastric tube from day 16 of gestation (date of retinal development) till delivery and continue for 20 days of lactation ${ }^{(8)}$. The other group, control $(n=5)$ that received only the vehicle in the same dose and route as hypothyroid group.

The pubs of control mothers $(n=$ 32) were divided into two equal 
subgroups, juvenile and adult that were sacrificed at day 20 and 60 postnatal respectively. While the pubs of hypothyroid mothers were separated into 2 major groups, hypothyroid model and thyroid supplement each was 32 . Hypothyroid model group alienated into juvenile subgroup, their mothers received the antithyroid drug during gestation and 20 days lactation and adult subgroups, the pubs themselves continuously receiving the hypothyroid agent orally until day 60 postnatal.

Thyroid supplementation:

The off springs of thyroid supplement group were similarly separated into 2 equal subgroups, juvenile and adult that received the same regimen as hypothyroid model groups then they were treated by L. thyroxine, Galaxo Wellcome Company, $10 \mathrm{ug} / \mathrm{kg}$ body weight orally by gastric tube for one month ${ }^{(9)}$.

\section{Physiological assays:}

The animals of each group were evaluated for No. of living pubs, body weight (gm) of the pubs, systolic blood pressure, heart rate, body temperature then they were anesthetized by an IP injection of cloral hydrate $(40 \mathrm{mg} / 100 \mathrm{~g}$ body $\mathrm{wt}$ ) and taken blood sample immediately before decapitation. Their serum and vitreous fluid were evaluated for levels of T3 and T4, IGF1, GH and LP, SOD, catalase, GSH-Px (U/mg $\mathrm{Hb})$.

Blood pressure: Systolic blood pressure was measured for all pubs at the end of experiment with a pneumatic tail-cuff device (NARCO, Biosystems, Inc., Houston, Texas) after the animal had been prewarmed for $30 \mathrm{~min}$. in a metal chamber maintained at approximately $30^{\circ} \mathrm{C}$. Three consecutive measurements were made at the same time of day. Mean systolic blood pressure value from three measurements was recorded as the pressure value for each animal.

Recording of heart rate with electrocardiogram: The pubs were anesthetized then needles of electrocardiograph were inserted in the skin of four limbs. The needle were connected to ECG recorder and counting the heart rate (ECG Cardiofax Nih Onkohn Kohden; Kogyo Co.Ltd, Japan).

Recording of body temperature: by insertion of a rectal thermistor probe (Cole-Parmer Instrument Company, Chicago, IL). The probe was $3.3 \mathrm{~mm}$ in diameter, and was lubricated with petroleum jelly. Each rat was held at the base of its tail as the probe was inserted $2.5 \mathrm{~cm}$ into the rectum. The probe was removed after the animal's temperature stabilized 30-60 sec later. The thermistor was accurate to $0.1^{\circ} \mathrm{C}^{(\mathbf{1 0 )}}$.

\section{Laboratory measurements:}

Blood samples were obtained from the jugular vein of anaesthetized animals immediately before sacrification. Samples were collected in both types of tubes with and without EDTA, and were centrifuged at 3000 r.p.m. for $20 \mathrm{~min}$ to separate serum, plasma and RBCs. Erythrocytes were washed three with saline then hae-molysed with an equal volume of distilled water. The plasma, serum and haemolysed RBCs were preserved at $-20{ }^{0} \mathrm{C}$ for assay.

Estimation of T3, T4, GH and IGF1: Enzyme-linked imunosorbent assays (ELISA) were performed for measuring concentrations of total 
triiodothyronine, total thyroxine, $\mathrm{GH}$, IGF-1 in serum; also GH and IGF-1 were measured in vitreous fluid using Biosurce Europe commercial kits with monoclonal antibodies against each substance and following the instruction supplied with each kit. The apparatus used was Ansoth, 2000 manufactured in Austria.

Estimation of Lipid Peroxidation: Lipid peroxidation products levels were measured in plasma according to the previous report of (11).

Estimation of SOD in plasma and catalase activity in hemolysates was done according to the reports of (12 and 13) respectively.

Estimation of antioxidant enzyme glutathione peroxidase (GSH-PX): level in RBCs was made following the report of (14). The values were then divided on hae-moglobin concentration/l. Haemoglobin concentration was determined following method described by the article of (15) through using Complete Hemoglobin reagent kits; (Merckotest, E. Merk, Darmstadt, Germany).

\section{Histological and Morphometric} analysis:

Both eyes from each pup were enucleated and placed in ice-cold phosphate-buffered saline (PBS; $\mathrm{pH}$ 7.4). Enucleation was performed with the use of iris forceps and scissors for separation of the eyes from the surrounding connective tissue, nerve, and muscles. The eyes were dried on sterile gauze, and the vitreous fluid was aspirated with a $0.5-\mathrm{mL}$ insulin syringe and placed on ice in sterile tubes (Eppendorf). Then the eyes were fixed in $4 \%$ gluteraldehyde and prepared for light and electron microscopic examinations.

The thickness of different layers of the retina was measured in toluidine blue stained sections, and cell count of the ganglion cell layer (linear cell density in number per unit length of the retina) was done. The measurements were performed using Image analyzer (Leica Q 500).

Statistical analysis:

Data are expressed as mean $\pm \mathrm{SE}$ for all parameters. The data were analyzed by using GraphPad Prism data analysis program (GraphPad Software, Inc., San Diego, CA, USA). For the comparison of statistical significance between different groups Student Newman-Keuls t-test for paired data were used. For multiple comparisons, one-way analysis of variance (ONE- WAY-ANOVA) test followed by least Significant Difference (LST) was used. Correlations were assessed using Spearman's non-parametric correlation coefficient $\rho$ according to that described by (16). A value of $\mathrm{P} \leq$ 0.05 was considered statistically significant.

\section{RESULTS}

In this study, we investigated the success of antithyroid drug, Neomercazole in induction of hypothyroid retinal degeneration model in rats and highlight on its pathophysiological mechanisms. Administration of L. thyroxine ameliorates to some extent theses effects. A summary of these results is shown in tables 1-3, histogram 1-6 and figures 1-18.

Intake of antithyroid agent was associated with reduction of No. of 
living pups, body weight, temperature and heart rate while increase systolic blood pressure of both subgroups when compared with their corresponding age and sex matched controls. Treatment with Lthyroxine for one month ameliorated significantly these changes especially in juvenile subgroup as shown in table 1.

Results of measured laboratory parameters:

Relation to serum levels of T4 and

T3: Estimation of serum levels of both T4 and T3 showed a significant decrease in both subgroups of hypothyroid model rats when compared with their control euthyroid subgroups. The reduction was obvious in adult subgroup of hypothyroid model. Treatment with L. thyroxine increased significantly the levels of $\mathrm{T} 4$ and $\mathrm{T} 3$ in both subgroups (Table 2).

Relation to lipid peroxidation and antioxidants (SOD, CAT and GSHPx): Compared with the control euthyroid group, LP products significantly increased while the levels of measured antioxidants decreased in hypothyroid model subgroups. An administration of L. thyroxine was associated with significant improvement in the plasma level of LP and antioxidants when compared with hypothyroid model subgroups and the response was manifested more in juvenile thyroid supplement subgroup (Table 2).

Relation to GH and IGF-1 levels in serum and vitreous fluid: Estimation of serum and vitreous levels of both GH and IGF-1 in both Euthyroid subgroups revealed two folds increase in their levels in vitreous fluid. Also, statistical analysis showed significant $(\mathrm{P}<0.001)$ increase $\mathrm{GH}$ and IGF-1 in juvenile subgroup of control when compared with adult subgroup. Intake of antithyroid agent decreased significantly $\mathrm{GH}$ and IGF-1 in serum and vitreous of both hypothyroid subgroups in comparable to their control subgroups. Treatment with L. thyroxine for one month restored significantly their levels especially in juvenile subgroup (Histograms 1, 2).

\section{Correlation and Regression} Analysis:

In both hypothyroid rat model subgroups, there was a statistically significant positive correlation between serum $\mathrm{T} 4$ and serum $\mathrm{GH}$, IGF-1 and antioxidants (SOD, CAT and GSH-Px) while negative relation with LP products (Histograms 3-6).

3-4. Histological results:

In the juvenile hypothyroid subgroup, the main finding was a reduction in the thickness of different retinal layers (Fig. 4,5 and 6) which attributed to the reduction in the photoreceptor cell layer, inner nuclear layer and ganglion cell layer in comparison to corresponding control subgroup (Fig. 1,2 and 3). Electron microscopic examination showed degenerative changes with distortion and vacuolation of most layers. Distortions of the mitochondria were also observed. Juvenile thyroid supplement subgroup (fig. 7, 8, 9), light microscopic examination revealed significant increase in the thickness of all cell layers in comparison to the hypothyroid one. Normal ganglion cells that arranged in a double discontinuous row with marked recovery in most studied 
layers that became similar to that of the control were also noticed.

Adult hypothyroid subgroup (Fig. 13, 14 and 15) showed marked reduction in the mean thickness of different retinal layers with marked alteration and degenerative changes in comparison to the corresponding control (Fig.10, 11 and 12). While, adult thyroid supplement subgroup (fig. 16, 17, 18), showed minimal improvement in the retinal layers in comparison to the adult hypothyroid subgroup. Significant reduction in the thickness of different layers associated with degenerative changes in most layers was still observed.

Morphometric results (table 3):
The morphometric findings revealed presence of significant decrease in the total thickness of the retina and its layers (photoreceptor layer, outer nuclear layer and inner nuclear layer) in both hypothyroid subgroups when compared to their corresponding controls. In the juvenile rat subgroup supplemented with 1thyroxine, there was a significant $(\mathrm{P}<0.001)$ improvement in all retinal layers when compared with hypothyroid subgroup. Also, estimation of the retinal layers in the adult thyroid supplement subgroup showed significant enhancement from hypothyroid model subgroup.

Table 1: Comparison mean values of survival rate, body temperature, blood pressure, heart rate in control, hypothyroid model and thyroid supplement rat groups.

\begin{tabular}{|l|l|l|l|l|l|l|}
\hline \multirow{2}{*}{ Groups/ Items } & \multicolumn{2}{|l|}{$\begin{array}{l}\text { Group A } \\
\text { Control (Euthyroid) }\end{array}$} & \multicolumn{2}{l|}{$\begin{array}{l}\text { Group B } \\
\text { (hypothyroid model ) }\end{array}$} & \multicolumn{2}{l|}{$\begin{array}{l}\text { Group C } \\
\text { Thyroid H supplement }\end{array}$} \\
\cline { 2 - 7 } & Subgroup I & Subgroup II & Subgroup I & Subgroup II & Subgroup I & Subgroup II \\
\hline Survival rate & $14 / 16$ & $15 / 16$ & $10 / 16$ & $12 / 16$ & $13 / 16$ & $13 / 16$ \\
\hline $\begin{array}{l}\text { No. of living } \\
\text { rats }\end{array}$ & 14 & 15 & 10 & 12 & 13 & 13 \\
\hline $\begin{array}{l}\text { Body weight } \\
\text { (gm) }\end{array}$ & $82.5 \pm 5.7$ & $138.3 \pm 18.3$ & $\begin{array}{l}53.2 \pm 6.93 \\
* * *\end{array}$ & $\begin{array}{l}104.9 \pm 9.3 \\
* * *\end{array}$ & $\begin{array}{l}74.54 \pm 9.3 \\
€ € €\end{array}$ & $\begin{array}{l}132.5 \pm 12.87 \\
€ € €\end{array}$ \\
\hline $\begin{array}{l}\text { Body temp. } \\
\text { 0 C }\end{array}$ & $37.01 \pm 0.25$ & 37.16 & $\begin{array}{l}36.19 \pm 0.47 \\
* * *\end{array}$ & $\begin{array}{l}35.98 \pm 0.34 \\
* * *\end{array}$ & $\begin{array}{l}36.7 \pm 0.28 \\
€ €\end{array}$ & $\begin{array}{l}36.42 \pm 0.35 \\
€ €\end{array}$ \\
\hline $\begin{array}{l}\text { BP (mmHg) } \\
\text { (m) }\end{array}$ & $114 \pm 3.0$ & $116 \pm 2.9$ & $\begin{array}{l}133 \pm 2.27 \\
* * *\end{array}$ & $\begin{array}{l}148 \pm 5.4 \\
* * *\end{array}$ & $\begin{array}{l}121 \pm 4.1 \\
€ € €\end{array}$ & $\begin{array}{l}126 \pm 3.96 \\
€ € €\end{array}$ \\
\hline $\begin{array}{l}\text { Heart rate } \\
\text { (beats/m) }\end{array}$ & $225.5 \pm 6.88$ & $219 \pm 6.95$ & $\begin{array}{l}197.6 \pm 6.52 \\
* * *\end{array}$ & $\begin{array}{l}184 \pm 4.9 \\
* * *\end{array}$ & $\begin{array}{l}206 \pm 8.8 \\
€\end{array}$ & $\begin{array}{l}196 \pm 8.2 \\
€ € €\end{array}$ \\
\hline
\end{tabular}

Values represent mean \pm SD and were analyzed by a Student-3Newman-Keuls t-test. , Subgroup I and II of rats, Sacrificed at day 20 (juvenile subgroup) and 60 (adult subgroup) postnatal. ( $n=16$ in each subgroup), (*) Significance versus control group. (€) Significance of values in thyroid supplement subgroup versus its corresponding hypothyroidism subgroup, ***/ $(€)(€)(€)$ significant difference at $P<0.001$. 
Table 2: Alterations of levels of T4, T3, lipid peroxidation products LP, SOD, Catalase and glutathione peroxidase (GSH-PX) in hypothyroid model and thyroid supplement groups.

\begin{tabular}{|c|c|c|c|c|c|c|}
\hline \multirow[t]{2}{*}{ Groups/Items } & \multicolumn{2}{|c|}{$\begin{array}{l}\text { Group A } \\
\text { Control (Euthyroid) }\end{array}$} & \multicolumn{2}{|c|}{$\begin{array}{l}\text { Group B } \\
\text { (hypothyroid model) }\end{array}$} & \multicolumn{2}{|c|}{$\begin{array}{l}\text { Group C } \\
\text { Thyroid H supplement }\end{array}$} \\
\hline & $\begin{array}{l}\text { Subgroup } \\
\text { I } \\
(n=14)\end{array}$ & $\begin{array}{l}\text { Subgroup II } \\
(n=15)\end{array}$ & $\begin{array}{l}\text { Subgroup I } \\
(\mathrm{n}=10)\end{array}$ & $\begin{array}{l}\text { Subgroup II } \\
(n=12)\end{array}$ & $\begin{array}{l}\text { Subgroup } \\
\text { I } \\
(n=13)\end{array}$ & $\begin{array}{l}\text { Subgroup II } \\
(\mathrm{n}=13)\end{array}$ \\
\hline $\begin{array}{l}\text { SerumT4 } \\
(\mu \mathrm{g} / \mathrm{dl})\end{array}$ & $13.2 \pm 0.83$ & $12.76 \pm 0.68$ & $\begin{array}{l}6.1 \pm 0.1 .5 \\
* * *\end{array}$ & $\begin{array}{l}4.4 \pm 0.55 \\
* * *\end{array}$ & $\begin{array}{l}8.6 \pm 0.75 \\
€ € €\end{array}$ & $\begin{array}{l}7.9 \pm 0.76 \\
€ € €\end{array}$ \\
\hline Serum T3 (ng/l) & $0.9 \pm 0.1$ & $0.68 \pm 0.12$ & $\begin{array}{l}0.07 \pm 0,02 \\
* * *\end{array}$ & $\begin{array}{l}0.08 \pm 0.4 \\
* * *\end{array}$ & $\begin{array}{l}0.63 \pm 0.15 \\
€ € €\end{array}$ & $\begin{array}{l}0.55 \pm 0.11 \\
€ € €\end{array}$ \\
\hline LP (nmol/ml.) & $2.37 \pm 0.45$ & $2.41 \pm 0.47$ & $\begin{array}{l}4.96 \pm 0.5 \\
* * *\end{array}$ & $\begin{array}{l}5.2 \pm 0.49 \\
* * *\end{array}$ & $\begin{array}{l}4.37 \pm 0.46 \\
€ €\end{array}$ & $\begin{array}{l}4.7 \pm 0.54 \\
€\end{array}$ \\
\hline SOD $(\mathrm{nmol} / \mathrm{ml})$ & $4.89 \pm 0.37$ & $5.03 \pm 0.41$ & $\begin{array}{l}2.52 \pm 0.45 \\
* * *\end{array}$ & $\begin{array}{l}2.79 \pm 0.6 \\
* * *\end{array}$ & $\begin{array}{l}3.74 \pm 0.58 \\
€ € €\end{array}$ & $\begin{array}{l}3.33 \pm 0.69 \\
€\end{array}$ \\
\hline $\begin{array}{l}\text { Catalse(U/mg } \\
\mathrm{Hb})\end{array}$ & $0.58 \pm 0.05$ & $0.62 \pm 0.04$ & $\begin{array}{l}0.42 \pm 0.05 \\
* * *\end{array}$ & $\begin{array}{l}0.36 \pm 0.04 \\
* * *\end{array}$ & $\begin{array}{l}0.53 \pm 0.04 \\
€ € €\end{array}$ & $\begin{array}{l}0.44 \pm 0.05 \\
€ € €\end{array}$ \\
\hline $\begin{array}{l}\text { GSH-Px(U/mg } \\
\text { Hb) }\end{array}$ & $58.3 \pm 0.8$ & $58.5 \pm 0.7$ & $\begin{array}{l}53.2 \pm 2.1 \\
* * *\end{array}$ & $\begin{array}{l}51.6 \pm 1.4 \\
* * *\end{array}$ & $\begin{array}{l}55.1 \pm 0.9 \\
€ €\end{array}$ & $\begin{array}{l}53.1 \pm 1.4 \\
€\end{array}$ \\
\hline
\end{tabular}

Values represent mean \pm SD and were analyzed by a Student-3Newman-Keuls t-test., Subgroup I and II, Sacrificed at day 20 (juvenile subgroup) and 60 (adult subgroup) postnatal. ( $n=16$ in each subgroup), (*) Significance versus control group.

$(€)$ Significance of values in thyroid supplement subgroup versus its corresponding hypothyroidism subgroup, $* * * /(€)(€)(€)$ significant difference at $P<0.001$, $\mathbf{8} / €$ significant difference at $P<0.05$, **/ €€ significant difference at $P<0.01$.
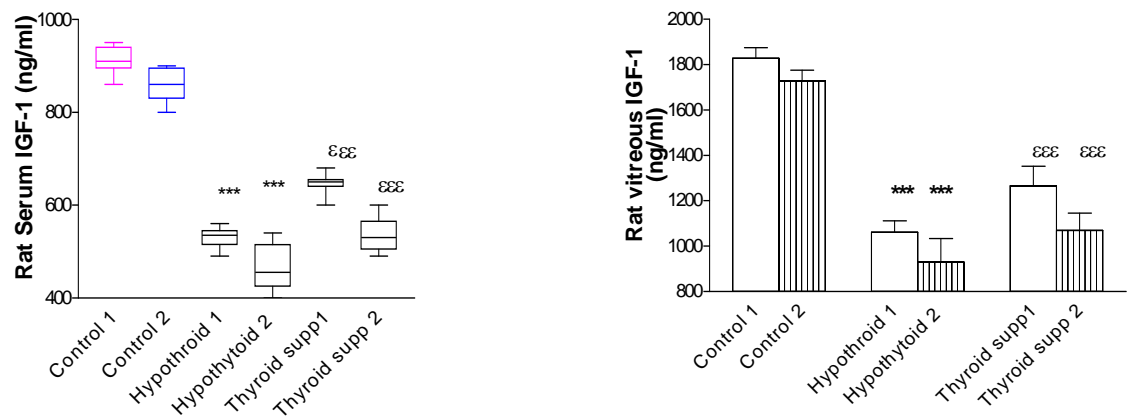

Histogram 1. Serum and vitreous IGF-1(mean \pm SD from individual rats were analyzed by a Student-3Newman-Keuls t-test. Levels of IGF-1 were decreased in all (Carbimazole) treated rats in a dose of $0.05 \mathrm{mg} \mathrm{mg} /$ day/pregnant female during gestation and lactation, subgroups I and II, Sacrificed at day 20 (juvenile subgroup) and 60 (adult subgroup) postnatal respectively. The IGF-1 increases more in thyroid supplement subgroup 1. ( $\mathrm{n}=16$ in each subgroup),

(*) Significance versus control group. (€)Significance of values in thyroid supplement subgroup versus its corresponding hypothyroidism subgroup, $* * * /$ significant difference at $\mathrm{P}<0.001$. 

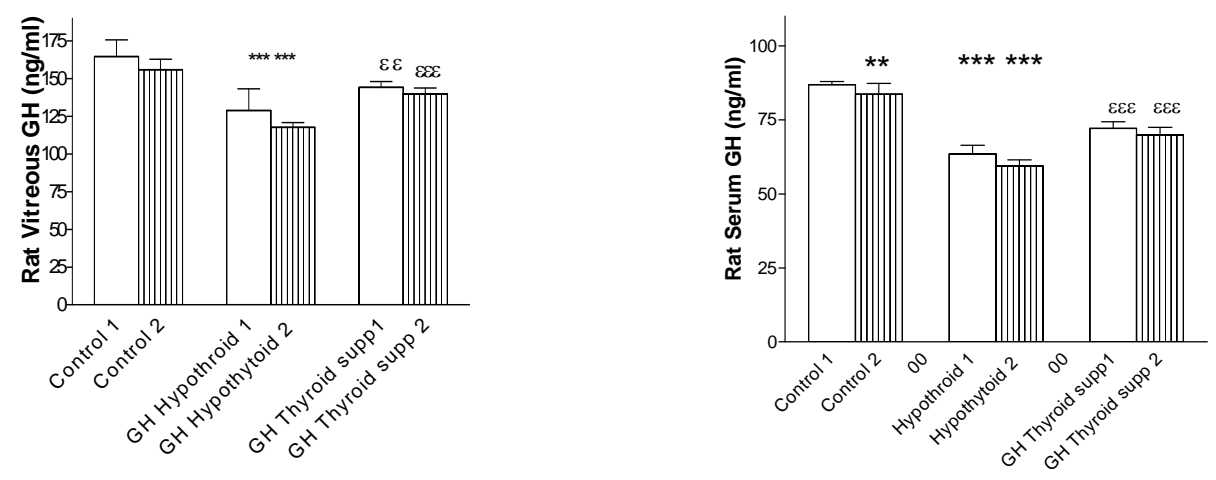

Histogram 2. Serum and vitreous GH (mean \pm SD from individual rats were analyzed by a Student-3Newman-Keuls t-test. Levels of $\mathrm{GH}$ were decreased in all (Carbimazole) treated rats in a dose of $0.05 \mathrm{mg} / \mathrm{day} /$ pregnant female during gestation and lactation, subgroups I and II, Sacrificed at day 20 (juvinealal subgroup) and 60 (adult subgroup) postnatal respectively. The GH increases more in thyroid supplement subgroup 1. ( $\mathrm{n}=16$ in each subgroup), $(*)$ Significance versus control group. $(€)$ Significance of values in thyroid supplement subgroup versus its corresponding hypothyroidism subgroup, ${ }^{* * *}$ / significant difference at $\mathrm{P}<0.001$.
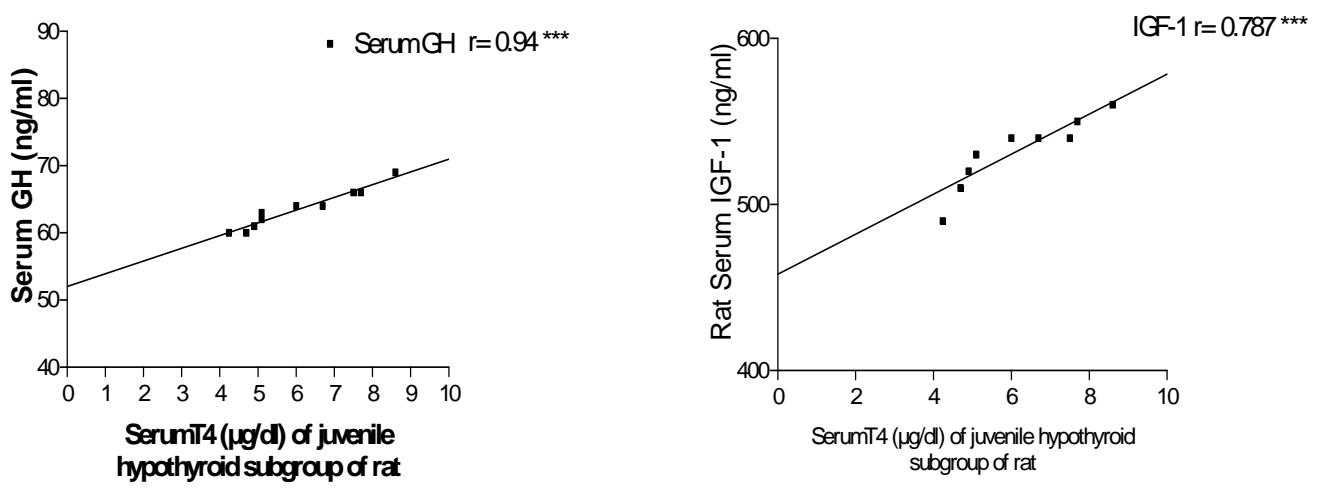

Histogram 3. Correlation and linear regression of serum T4 with GH and IGF-1 in hypothyroid rat model (Juvenile subgroup) sacrificed at day 20 postnatal. A positive, significant relationship was noted between serum T 4 and GH and IGF-1. 

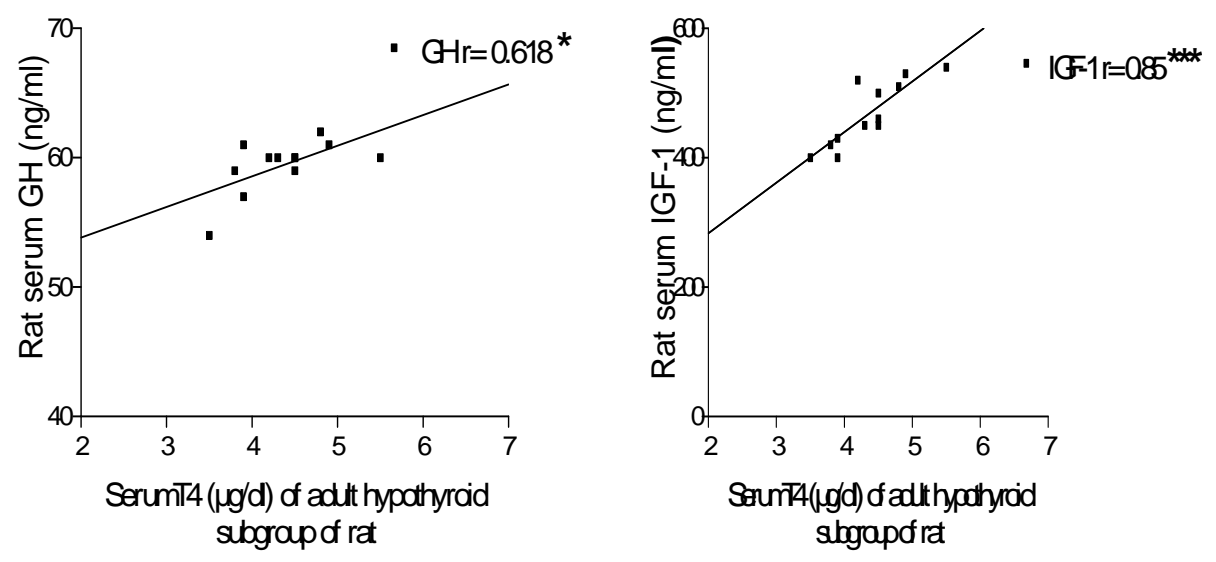

Histogram 4. Correlation and linear regression of serum T4 with GH and IGF-1 in hypothyroid rat model (adult subgroup) sacrificed at day 60 postnatal. A positive, significant relationship was noted between serum T 4 and GH and IGF-1.
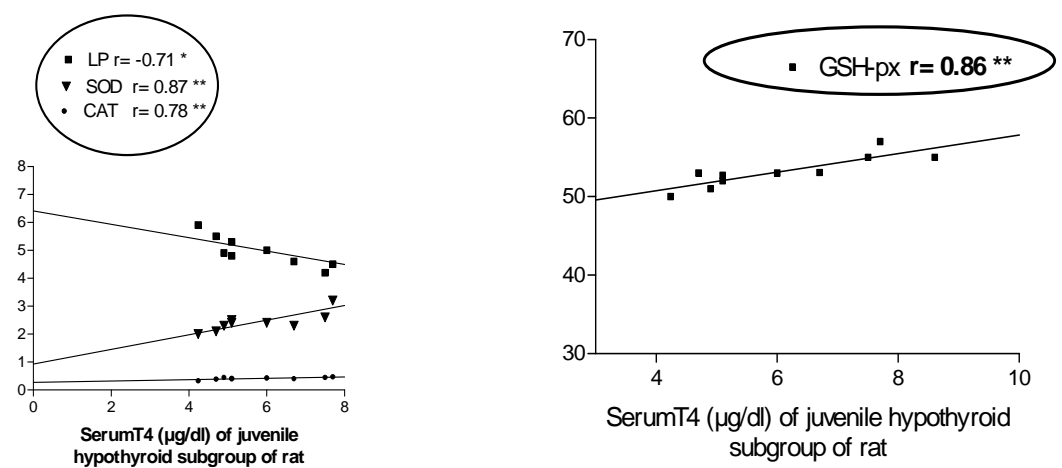

Histogram 5: Correlation and linear regression of serum T4 with LP and antioxidants (SOD, CAT and GSH-px) of juvenile hypothyroid subgroup of rat. A positive, significant relationship was observed between serum T 4 with SOD, CAT, GSH-px and negative with LP. 

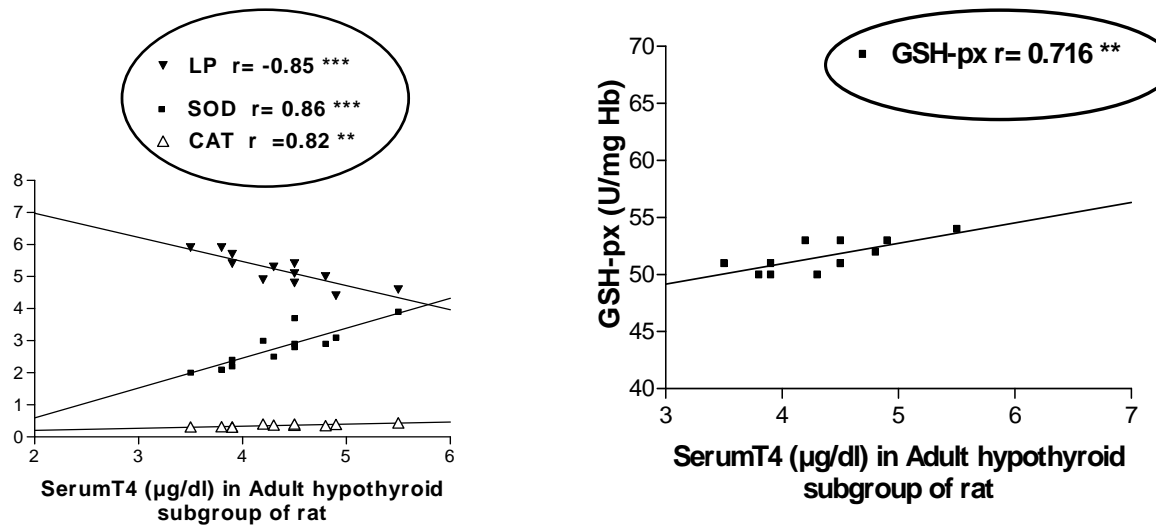

Histogram 6: Correlation and linear regression of serum T4 with LP and Antioxidants (SOD, CAT and GSH-px) of adult hypothyroid subgroup of rat. A positive, significant relationship was noted between serum T 4 with SOD, CAT, GSH-px and negative with LP.

Table (3): Alteration of thickness of the retina and its layers ( $\mathrm{mm}$ ) in hypothyroid model and thyroid supplement groups. The data was represented as mean $\pm \mathrm{SD}$.

\begin{tabular}{|c|c|c|c|c|c|c|}
\hline & \begin{tabular}{|l|l|} 
Group A \\
Control (Eut
\end{tabular} & thyroid) & \begin{tabular}{|l|}
$\begin{array}{l}\text { Group B } \\
\text { (Hypothyroi }\end{array}$ \\
\end{tabular} & model) & \begin{tabular}{|l|} 
Group C \\
Thyroid H s \\
\end{tabular} & ement \\
\hline & \begin{tabular}{|l|}
$\begin{array}{l}\text { Subgroup I } \\
(\mathrm{n}=14)\end{array}$ \\
\end{tabular} & $\begin{array}{l}\text { Subgroup II } \\
(\mathrm{n}=15)\end{array}$ & $\begin{array}{l}\text { Subgroup I } \\
(\mathbf{n}=10)\end{array}$ & $\begin{array}{l}\text { Subgroup II } \\
(n=12)\end{array}$ & $\begin{array}{l}\text { Subgroup I } \\
(n=13)\end{array}$ & $\begin{array}{l}\text { Subgroup II } \\
(\mathrm{n}=13)\end{array}$ \\
\hline \begin{tabular}{|l|l|} 
Tota \\
thick
\end{tabular} & $0.30 \pm 0.01$ & $0.36 \pm 0.04$ & $\begin{array}{l}0.18 \pm 0.06 \\
* * *\end{array}$ & $\begin{array}{l}0.15 \pm 0.06 \\
* * *\end{array}$ & $\begin{array}{l}0.31 \pm 0.003 \\
€ € €\end{array}$ & $0.19 \pm 0.1$ \\
\hline $\begin{array}{l}\text { Photoreceptor layer } \\
(\mathbf{P})\end{array}$ & 9 & 0.15 & \begin{tabular}{|l|}
$0.04 \pm 0.005$ \\
$* * *$
\end{tabular} & \begin{tabular}{|l|}
$0.034 \pm 0.008$ \\
$* * *$
\end{tabular} & $\begin{array}{l}0.12 \pm 0.007 \\
\boldsymbol{€ € €}\end{array}$ & $\begin{array}{l}0.0 \\
€\end{array}$ \\
\hline $\begin{array}{l}\text { Outer nuclear layer } \\
\text { (ONL) }\end{array}$ & .004 & $\begin{array}{l}0.076 \\
0.005 \\
\end{array}$ & \begin{tabular}{|l|}
$0.05 \pm 0.005$ \\
$* * *$
\end{tabular} & \begin{tabular}{|l|}
$0.043 \pm 0.008$ \\
$* * *$
\end{tabular} & $\begin{array}{l}0.071 \pm 0.005 \\
\boldsymbol{\epsilon € €}\end{array}$ & $\begin{array}{l}0.054 \pm 0.011 \\
€ €\end{array}$ \\
\hline Inner nuclear layer & 006 & $\begin{array}{l}.058 \\
0.003 \\
\end{array}$ & \begin{tabular}{|l|}
$0.03 \pm 0.006$ \\
$* * *$
\end{tabular} & \begin{tabular}{|l|}
$0.023 \pm 0.01$ \\
$* * *$
\end{tabular} & $\begin{array}{l}0.056 \pm 0.007 \\
€ € €\end{array}$ & $\begin{array}{l}0.031 \pm 0.004 \\
€\end{array}$ \\
\hline $\begin{array}{l}\text { Ganglionic cell layer } \\
\text { (GL) }\end{array}$ & $0.03 \pm 0.004$ & $0.04 \pm 0.011$ & $\begin{array}{l}0.02 \pm 0.005 \\
* * *\end{array}$ & $\begin{array}{l}0.020 \pm 0.001 \\
* * *\end{array}$ & $\begin{array}{l}0.038 \pm 0.008 \\
\boldsymbol{\epsilon € €}\end{array}$ & $\begin{array}{l}0.024 \pm 0.003 \\
\boldsymbol{\epsilon € € ~}\end{array}$ \\
\hline
\end{tabular}

Values represent mean $\pm S D$ and were analyzed by a Student-3Newman-Keuls t-test. Subgroup I and II, Sacrificed at day 20 (juvenile subgroup) and day 60 (adult subgroup) postnatal. (*) Significance versus control group. (€) Significance of values in thyroid supplement subgroup versus its corresponding hypothyroidism subgroup, $* * * /(€)(€)(€)$ significant difference at $P<0.001$, */ $€$ significant difference at $P<0.05$, $* * / € €$ significant difference at $P<0.01$. 

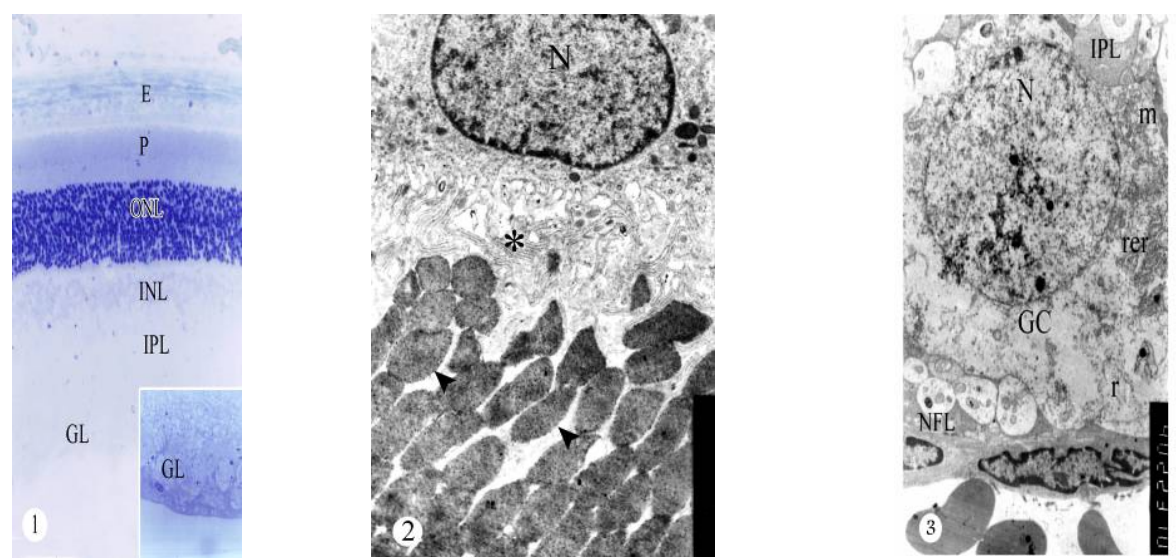

Fig.1, 2 and 3: A semithin section of the juvenile retina of control albino rat: (a) showing; epithelial layer $(\mathrm{E})$, photoreceptor layer $(\mathrm{P})$, outer nuclear layer $(\mathrm{ONL})$, inner nuclear layer (INL), inner plexiform layer (IPL) and ganglion cell layer (GCL). (b) a magnified part of GCL showing; normal arrangement of ganglion cells. (Toluidine blue X 200, X1000). Electron microscopic examination showing; a part of epithelial and photoreceptor layers, structures of the photoreceptors outer segment (x 5000) (Fig. 2), inner plexiform layer (IPL) and ganglionic cell layer can be seen in figure $3(\mathrm{x} 4000)$.
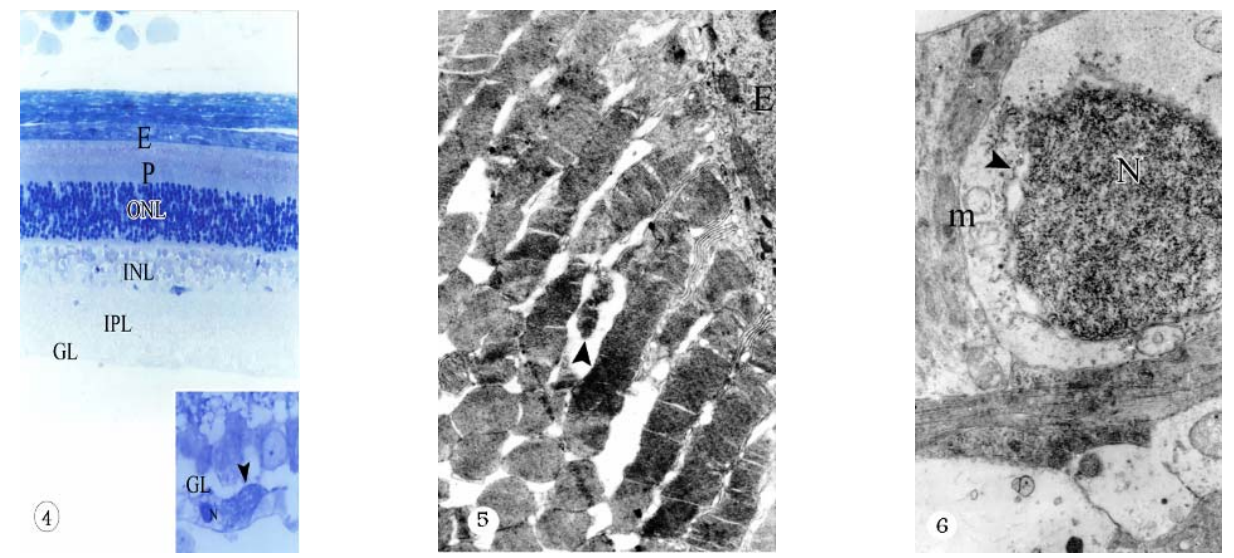

Fig.4, 5 and 6: A semithin section of the juvenile retina of hypothyroid subgroup: showing reduction of the thickness of most layer, disturbed architecture of GCL with shrunken and degeneration of some ganglion cells (X200 , X 1000). EM examination showing: distortion and degeneration of the outer segment of photoreceptors. Bleb -like protrusion (arrow) of the surrounding plasma membrane is noticed (x 5000) (Fig. 5). Degenerated ganglion cell with dense granular nucleus $(\mathrm{N})$ surrounded by rarefied cytoplasm, dilated nuclear envelope (arrowhead) and mitochondria with destructed cristae can also be noticed (m) in figure 6 (X10000). 

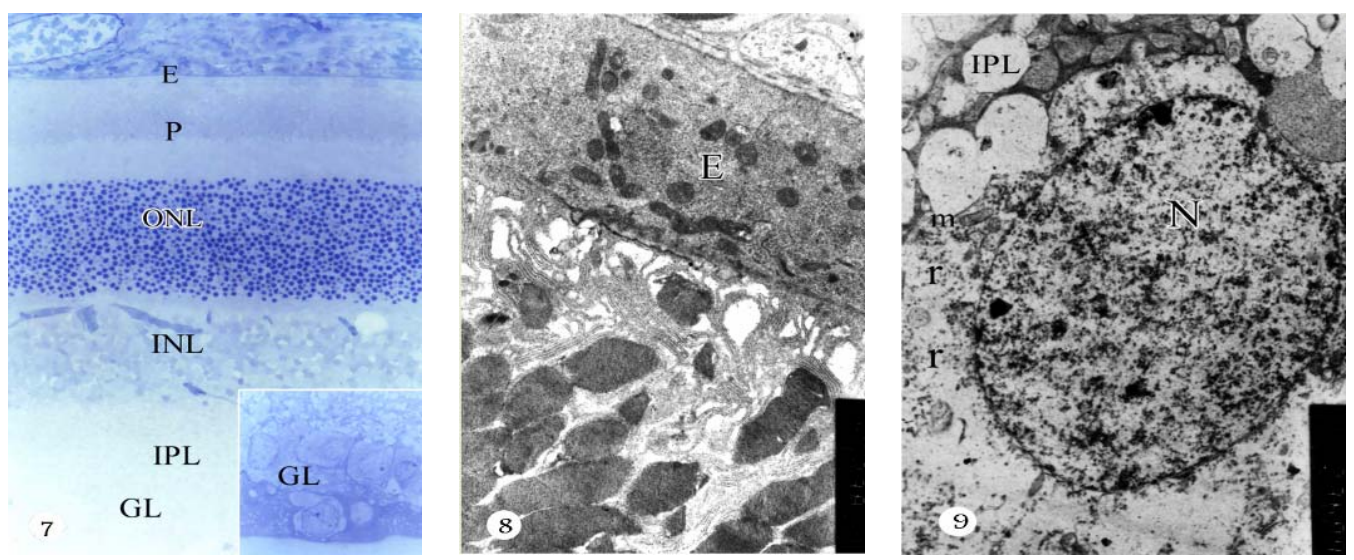

Fig.7, 8 and 9: A semithin section in the juvenile retina of thyroid supplement group showing recovery of the thickness of most layers which appear similar to that of the control. A magnified part of GCL showing; normal appearance of ganglion cells (Toluidine blue X 200, $\mathrm{X} 1000)$.EM examination showing recovery of the of the outer segment of the photoreceptors ( $\mathrm{X}$ 5000) (Fig. 8), normal ganglion cell with large rounded nucleus (N) and the cytoplasm contains ribosomes (r) and small sized mitochondria (m). (X 000)(Fig. 9).
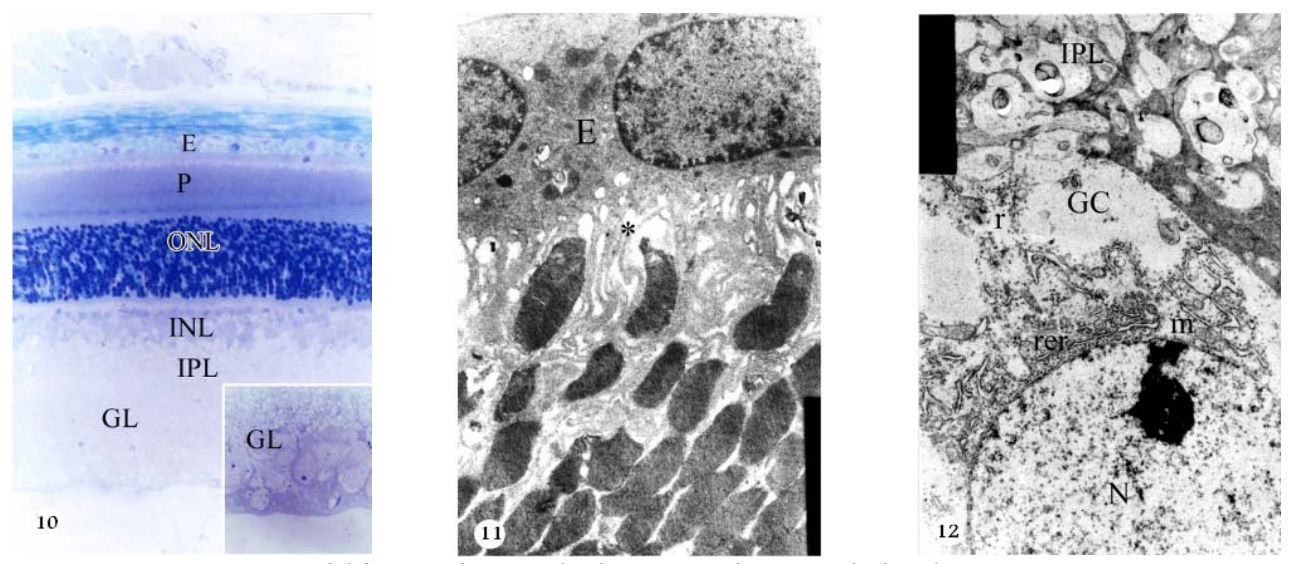

Fig. 10, 11, 12: A semithin section and electron micrograph in the retina of adult control albino rat subgroup showing: the same layers as in juvenile control subgroup. 

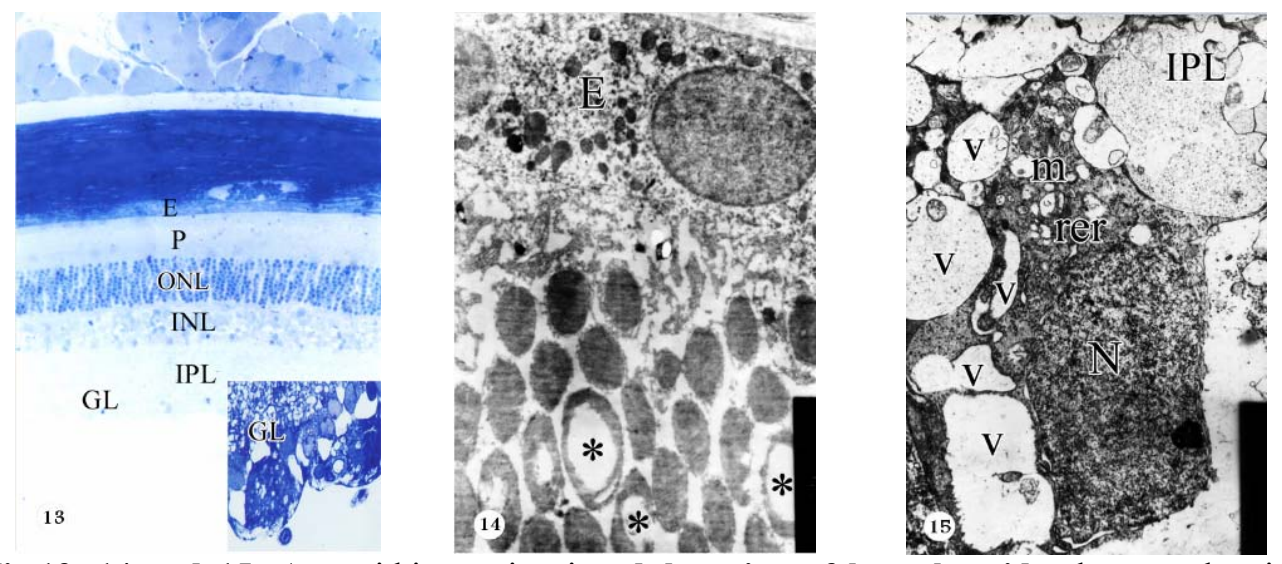

Fig.13, 14 and 15: A semithin section in adult retina of hypothyroid subgroup showing; reduction of the thickness of most layer, (Toluidine blue X 200). Distortion, degeneration and decrease in the density of the outer segment of photoreceptors. Central degeneration in the lamellae is noticed (*) (X000) (fig. 14). A group of degenerated amacrine cells (AM) with rarefied cytoplasm. Some nuclei $(\mathrm{N})$ appear dense with dilated nuclear envelope. No cell organelles can be seen (X000) (fig. 15).
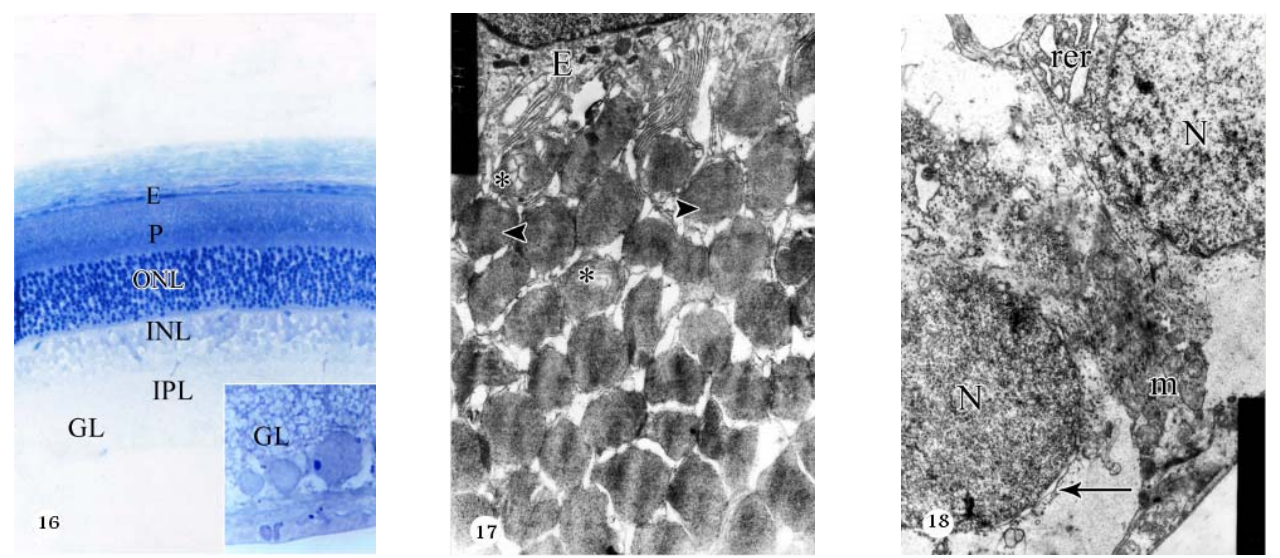

Fig.16, 17 and 18: A semithin section of the retina of adult thyroid supplement subgroup showing: reduction of the thickness of most layers is still present. Inset: A magnified part of GL showing; ganglion cells with minimal recovery. (Toluidine blue X200, X 1000). Electron microscopic examination showing: partial recovery of the epithelial and the outer segment of photoreceptor layers. Central degeneration of disc membrane is observed $(*)$. Some of them are converted into an amorphous electron-dense mass (arrowhead) (X000) (fig. 17). Two ganglion cells with rarefied cytoplasm and small degenerated mitochondria (m) were still notice (X000) (fig. 18). 


\section{DISCUSSION}

$\mathrm{TH}$ is the critical regulator for normal growth and physiological functions of retinal receptors specially cones as described by ${ }^{(17)}$. However, the pathophysiological mechanisms of hypothyroid retinal degeneration and the involvement of GH, IGF-1 and oxidative stress in this case is still debated. In this investigation, we hypothesized that thyroid supplement can ameliorate the experimental model of hypothyroid retinal degeneration. To accomplish our goals, we established an animal model formed of control, hypothyroid model and L. thyroxine treated groups.

In this study, antithyroid agent, Carbimazole either in juvenile and adult rat, succeeded in induction of hypothyroid model of retinal degeneration that was associated with: (i) reduction in the number of living pubs, body weight, body temperature, heart rate and increase in systolic blood pressure, (ii) dramatic decrease in the blood levels of T3, T4 and reduction in thickness and cell numbers in all retinal layers. Besides, treatment with L-thyroxine for one month after induction of hypothyroid model in group $\mathrm{C}$, was associated with partial improvement of both physiological and structures alterations.

In the present work, suppression effects of hypothyroidism on the number of living pubs and body weight coincide with the reports of $^{(18,19)}$. This growth retardation may be caused by the increased competition for food or the decline of serum and vitreal GH and IGF-1 recorded in this study as supported by $^{(20)}$. Unfortunately, it is not possible to know the causes of death of pubs as often the mothers eat their dead pups. Thyroid supplement subgroups showed restoration of the body weight especially in juvenile subgroup that is consistent with the result of ${ }^{(21)}$.

The reduction of body temperature, heart rate and increase the systolic blood pressure in hypothyroid rat model subgroups recorded in this study and the amelioration which happened after TH supplementation are in lines with the results of ${ }^{(22,23 \& 24)}$. These effects are supported by many observations. Thyroid hormones regulate metabolism through hypothalamopituitary neuroendocrine feedback loops. In turn, decreased $\mathrm{T}_{3}$ output reduces metabolism and energy usage $^{(25)}$ and T4 administration rapidly increase the resting metabolic rate of hypothyroid rats and improve the survival of hypothyroid rats ${ }^{(26)}$. Also, Shoham et al. ${ }^{(27)}$ added that neonates with congenital hypothyroidism had significant reduction of fetal heart rate and this finding might be an early sign for fetal hypothyroidism. Furthermore, levothyroxin treatment to maternal hypothyroidism patients improved heart rate reduction ${ }^{(28)}$.

In juvenile hypothyroid model subgroup of the current study, deprivation of thyroid hormone seemed to interfere with normal development of the retina, decrease in the total thickness of all retinal layers and induce ultrastrural degeneration in most retinal layers that in accord with finding of ${ }^{(29)}$. They reported that the 
congenitally hypothyroid rats had significantly smaller and thinner retinas, with fewer dividing progenitor cells.

Moreover, morphometric results of hypothyroid subgroups in the present article revealed significant reduction of total retinal thickness and all retinal layers. These results can be explained by studies of ${ }^{(17,30)}$ who reported that thyroid hormone acts directly at the transcription level by binding to nuclear receptors to control a number of physiological and developmental processes. Also, hypothyroidism may depress ventilation leading to hypoxemia and decrease blood vessel density, which in turn reduces delivery of oxygen and nutrients to tissues ${ }^{(31)}$.

In the current work, supplementation with L-thyroxine showed amelioration of most degenerative and morphometric changes also, photoreceptors and ganglion cells restored their normal organization that agrees with study of Pinazo-Durán et al. ${ }^{(2)}$. This improvement was markedly in the juvenile subgroup who received the Lthyroxine early. But there was marked resistance to cell recovery in the adult subgroup who received the Lthyroxine after achieving the adolescence.

In the current investigation, the two folds increase in the vitreal levels of $\mathrm{GH}$ and IGF-1 than that of the serum was recorded in both juvenile and adult control subgroups. This finding may reveal their potential roles in the normal visual growth. This result is in consistency with the study of ${ }^{(32)}$. Also, the study of ${ }^{(33)}$ reported that the aqueous and vitreous humor fluids are potential sites of synthesis of IGF-binding proteins that can explain their high concentration of $\mathrm{GH}$ and IGF-1, so the vitreous fluid acts as a reservoir for stabilizing visual physiology. Ziaei et al. ${ }^{(34)}$ added that low GH concentrations in the vitreous of diabetic patients may correlate with retinal neurodegeneration and may provide a marker to follow its progression.

In this investigation, retinal degeneration proofed after thyroid deprivation may be mediated by the recorded reduction in the serum and vitreous GH and IGF-1 as well as increase serum lipid peroxidation products and decrease antioxidants (SOD, CAT and GSH-px) in both hypothyroid subgroups. In addition, the deviation in the levels of $\mathrm{GH}$, IGF-1, LP and antioxidants has been corrected partially after 1- thyroxine supplementation especially in juvenile subgroup.

The decline in the serum and vitreous $\mathrm{GH}$ in the current work after medical thyroidectomy by carbimazole is in consistent with the results of ${ }^{(6,9 \& 34)}$. They reported that vitreal growth factors regulate retinal function $^{(34)}$, act as be neuroprotective factor for retinal ganglion cells and provide markers of ocular degeneration as in case of hypothyroidism (35 and 20). Also, GH may act by induction of the IGF-I system or directly through its receptor $^{(36)}$.

It has been summarized that hypothyroid retinal degeneration in this work may be mediated by lowerthan-normal IGF-1 in serum and vitreous fluid that coincides with the reports of ${ }^{(37 \& 18)}$. They found that 
exposing neonatal rats to anti-thyroid drug suppresses serum IGF-1. Also, previous studies suggested that IGF-1 is a potent growth promoter of retinal endothelial cells and retinal pericytein $^{(3)}$ and is critical for normal retinal vascular growth and function.

In addition, a significant positive relationship between serum T4 with serum GH and IGF-1 was evident in both hypothyroid subgroups of rats that proved the association between hypothyroid retinal degeneration with suppression of GH and IGF-1. This result is in accordance with the other studies that confirmed an important link between IGF-1 and normal and abnormal retinal physiology and verify that IGF-1 is a vital modulator of thyroid activity ${ }^{(3)}$. Also, premature infants are more likely to have low $\mathrm{T}_{4}$ levels and $\mathrm{GH}$, indicating an abnormal hypothalamus-pituitary-thyroid axis function $^{(38)}$.

Alteration of plasma levels of LP and antioxidants (significant, $P$ $<0.001$ increase of LP products and decrease of SOD, CAT and GSH-px) in both hypothyroid model subgroups that manifested in this study harmonizes with other investigations. The searches of ${ }^{(7 \& 39)}$ found that hypothyroidism induces selective oxidative stress (increase levels of malondialdehyd, and decrease levels of CAT in liver, the hippocampus and amygdale. These changes in the levels of lipid peroxidation and antioxidant enzymes which were noticed in hypothyroid rats may explain retinal degeneration in these animals. The study of ${ }^{(40)}$ found that hypothyroidism was associated with enhanced oxidative stress and lipid peroxidation, and showed a significant decrease SOD activity and the activities of the enzymes GSH-Px and CAT in hypothyroid patients compared to controls.

The present study reports that thyroid supplementation for one month can modify the oxidants changes induced by intake of carbimazole, as it decreased significantly the levels of LP products and increased the antioxidants (SOD, CAT and GSH-px) especially in juvenile subgroup of rats. Although the pathophysiological consequences of the decelerated antioxidant levels are not yet elucidated, this biochemical change in the level of free radical and antioxidant is thought to be a physiological adaptation and response to hypothyroidism as a chronic state of hypothyroidism is characterized by degenerations in the redox potential. This leads to free radical chain reactions and metabolic suppression of antioxidant capacity. Thus, it is likely that retinal' cells may be damaged by prolonged oxidative stress that far exceeds the capacity of the tissue to synthesize antioxidants.

Moreover, in the present work, significant positive relationships were evident between serum T4 and antioxidants (SOD, CAT and GSH$\mathrm{Px}$ ) while negative relation with LP products in both hypothyroid subgroups. This finding confirms the potential role of oxidative stress as a mediator for retinal degeneration in hypothyroid rat that agrees with study of ${ }^{(39)}$.

\section{CONCLUSION}

This work indicates that Carbimazole, antithyroid agent, 
successes in induction of hypothyroid retinal degeneration model in rats which is mediated by suppression of $\mathrm{GH}$, IGF-1 and increase oxidative stress. Also, 1-thyroxine administration can blunt the metabolic pathologies and morphological changes induced by antithyroid agent. A better understanding is needed for the molecular pathophysiological factors involved in retinal degeneration so that new methods of prevention and treatment can be developed. In addition, this study recommends, blood testing for hypothyroid patients' T4, GH, IGF-1 and antioxidant system in order to monitor the progression of pathology and to prompt the consideration of medical care.

\section{REFERENCES}

1. Bianco AC, Salvatore DU, Gereben BB, Berry, M, and Larsen, P. Endocr. Rev 2002; 23:38-89.

2. Pinazo-durán MD, Iborra FL, Pons SU, Sevilla-romero E, Gallego-pinazo R, and Muñoz M R. Postnatal thyroid hormone supplementation rescues developmental abnormalities induced by congenital-neonatal hypothyroidism in the rat retina. Ophthalmic Res 2005; 37:225-34.

3. Hellstrom A, Carlsson B, Niklasson A, et al. IGF-I is critical for normal vascularization of the human retina. J Clin Endocrinol Metab 2002;87:341316.

4. Hellstrom A, Engstrom E, Hard AL, et al. Postnatal serum insulin-like growth factor I deficiency is associated with retinopathy of prematurely and other complications of premature birth. Pediatrics 2003;112:101620.

5. Kirsten D. The thyroid gland: physiology and pathophysiology. Neonatal Network. 2003;19:1126. [ Influence of hypothyroidism on lipid peroxidation, erythrocyte resistance and antioxidant plasma properties in rabbits. Author: Ewa Brzeziñska-CElebodziñska

Source: Acta Veterinaria Hungarica, Volume 51, Number 3, 30 July 2003 , pp. 343-51.

6. Harvey $S$, Eve $P$, Ian $M$ and Esmond J S. Growth hormone is present in the human retina and vitreous fluid. Neuroscience Letters 2009; 455:199-02

7. Yilmaz S, Sema O, Fulya B and Halit C. Oxidative damage and antioxidant enzyme activities in experimental hypothyroidism. Cell Biochemistry and Function 2003; 21: 325 - 330

8. Dakin OC and Grino M. Effect of experimental hypothyroidism on the development of the hypothalamo-pituitary-adrenal axis in the rat. Life Sci 2000; 23: 2827-44.

9. Prasad R, Kumar V, Kumar R and Palsingh K. Thyroid hormones modulate zinc transport activity of rat intestinal and renal brush border membrane. Am. J. physiol 1999; 276: E774- 82.

10. Marks A, Vianna $D$ and Carrive P. Nonshivering thermogenesis without interscapular brown adipose tissue involvement during conditioned fear in the rat. Am. J. 
Physiol. Regul. Integr. Comp. Physiol. 2009; 296: R 1239- 47.

11. Aruoma OI, Langhton MJ and Gutteridge JM. The mechanism of initiation of lipid peroxidation. Evidence against a requirement for an iron (II) -iron (III) complex. Biochem. J 1989; 258: $627-30$.

12. Misra $H$ and Fridovich $I$. The role of superoxide anion in the autooxidation of epinephrine and a simple assay for superoxide dismutase. J. Biol. Chem 1972; 215: 3170-75.

13. Luck H. Catalase. In: Bergmeyer, H.U. (Ed), Methods of enzymatic Analysis. Academic Press, New York, 1963 pp885-88.

14. Hafeman DG, Sunde RA et al. Effect of dietary selenium on erythrocyte and liver glutathione peroxidase in the rat. J Nutr 1974; 104: 580-87.

15. Crosby WH, Munn JI and Furth FW. Standardizing method for clinical hemogobinometry. Armed forces Med J 1954; 5: 693-03.

16. Knapp GR and Miller MC. Tests of statistical significance: Regression and correlation. In: Clinical Epidemiology and Biostatistics1992; PP:255-274. $1^{\text {st }}$ Edition. William \& Wilkins, Baltimore, Maryland.

17. Lu A, Ng L, Ma M, Kefas B, Davies TF, Hernandez A, Chan CC, Forrest D. Retarded developmental expression and patterning of retinal cone opsins in hypothyroid mice. Endocrinology 2009; 150:153644.
18. Mookadam M, David A L, Michael P F, William $L$ L and Jonathan M H. The Anti-thyroid Drug Methimazole Induces Neovascularization in the Neonatal Rat Analogous to ROP. Investigative Ophthalmology and Visual Science 2004;45:4145-50.

19. Carneiro-Ramos MS, Diniz GP, Almeida J, Vieira RL, Pinheiro SV, Santos RA, Barreto-Chaves ML. Cardiac angiotensin II type I and type II receptors are increased in rats submitted to experimental hypothyroidism. J Physiol 2007; 583: 213-23.

20. Löfqvist $C$, Ingrid Hansen-P, Eva A, Kristina H, Lois $\mathbf{E} \mathbf{H}$, David L, and Ann H. Validation of a New Retinopathy of Prematurity Screening Method Monitoring Longitudinal Postnatal Weight and Insulin like Growth Factor I. Arch Ophthalmol 2009; 127:622-27.

21. Schlenker EH, Megan H, Yingheng L, Rebecca A Redetzke, Eugene $M$, and Martin AG. Effects of thyroidectomy, T4, and DITPA replacement on brain blood vessel density in adult rats. Am J Physiol Regul Integr Comp Physiol 2008; 294: R1504-9.

22. Zaninovich A A, Inés R, Marcela R, Conrado $\mathbf{R}$, and Karl H. Mitochondrial respiration in muscle and liver from cold-acclimated hypothyroid rats. Appl Physiol 2003; 95: 1584-90.

23. Arruda $A$, Luisa $A$, Mariana N, Antonio G, Denise $P C$ and Leopoldo $M$. Cold Tolerance in Hypothyroid 
Rabbits: Role of Skeletal Muscle Mitochondria and Sarcoplasmic Reticulum $\mathrm{Ca} 2+$ ATPase Isoform 1 Heat Production. Endocrinology 2008; 149:626271.

24. Decherf S, Isabelle S, Soumaya K, Alejandra L J, MarieStéphanie $\mathbf{C} \mathbf{F}$ and Barbara $A$ D. Thyroid hormone exerts negative feedback on hypothalamic type 4 melanocortin receptor expression. Proc Natl Acad Sci U S A. 2010; 107: 4471-76.

25. Hollenberg AN. The role of the thyrotropin-releasing hormone (TRH) neuron as a metabolic sensor. Thyroid 2008;18:131-39.

26. Moreno M, Lombardi A, Lanni A, Beneduce L, Silvestri E, Goglia F. Are the effects of T3 on resting metabolic rate in euthyroid rats entirely caused by T3 itself? Endocrinol 2002; 143: 504-10.

27. Shoham I, Aricha-Tamir B, Wiznitzer A, Holcberg G, Sheiner E. Fetal heart rate tracing patterns associated with congenital hypothyroidism. Am J Obstet Gynecol 2009; 201:48-54.

28. Buscicchio G, Gentilucci L, Baldini E, Giannubilo S, Tranquilli AL. Computerized analysis of heart rate in fetuses from mothers under levothyroxin tretment. Gynecol Endocrinol 2009; 25:679-82.

29. Sevilla-Romero E, Muñoz A, and Pinazo-Durán MD. Low thyroid hormone levels impair the perinatal development of the rat retina. Ophthalmic Res 2002; 34:181-91.
30. Baas D, Le Grand C, Samarut J and Flamant $F$. Persistence of oligodendrocyte precursor cells and altered myelination in optic nerve associated to retina degeneration in mice devoid of all thyroid hormone receptors. Proc Natl A Cad Sci USA 2002; 99: 2907-11.

31. Saaresranta $T$ and Polo $O$. Sleep-disordered breathing and hormones. Eur Respir J 2003; 22: 161-72.

32. Modanlou HD, Zahra G, Jamal H, Joshua W, Stephen $N$ and Kay D A. Ontogeny of VEGF, IGF-I, and GH in Neonatal Rat Serum, Vitreous Fluid, and Retina from Birth to Weaning. Investigative Ophthalmology and Visual Science 2006;47:738-744.

33. Arnold DR, Moshayedi P, Schoen TJ, Chader GJ and Waldbillig RJ. Distribution of IGF-I, IGF binding proteins (IGFBPs) and IGFBP mRNA in ocular fluids and tissues: potential sites of synthesis of IGFBPs in aqueous and vitreous. Exp Eye Res 1993;56:555-65.

34. Ziaeia M, Matthew T, Esmond J. $S$ and Steve $H$. Vitreous growth hormone and visual dysfunction. Neuroscience Letters 460; 2009: 87-91.

35. Norman M, Lavin T, Baxter J, West B. The rat growth hormone gene contains multiple thyroid response elements. J Biol Chem 1989; 264: 12063-73.

36. LeRoith D. The Somatomedin hypothesis. Endocr Rev 2001; 22:53-74.

37. Bruce A. B, Hongmei $L$ and Robin L R. Effect of 
Methylimidazole-Induced

Hypothyroidism in a Model of

Low Retinal Neovascular Incidence. Investigative

Ophthalmology and Visual

Science 2004;45:919-21.

38. Walenkamp $M \quad J$ E and Wit $J$

M. Genetic disorders in the $\mathrm{GH}-$

IGF-I axis in mouse and man.

European

Journal

of

Endocrinology 2007; 157:S15-26.

39. Cano-Europa $E$, Francisca $P$ S,
José $\mathbf{S}$ and Jorge PR. Hypothyroidism induces selective oxidative stress in amygdala and hippocampus of rat. Metabolic Brain Disease 2008; 23: 275-87.

40. Seval Y, Sema O, Fulya B, Halit C. Oxidative damage and antioxidant enzyme activities in experimental hypothyroidism. Cell Biochemistry and Function 2003; 21:325-30.

Paula V, Rocío O B, Camilo R,

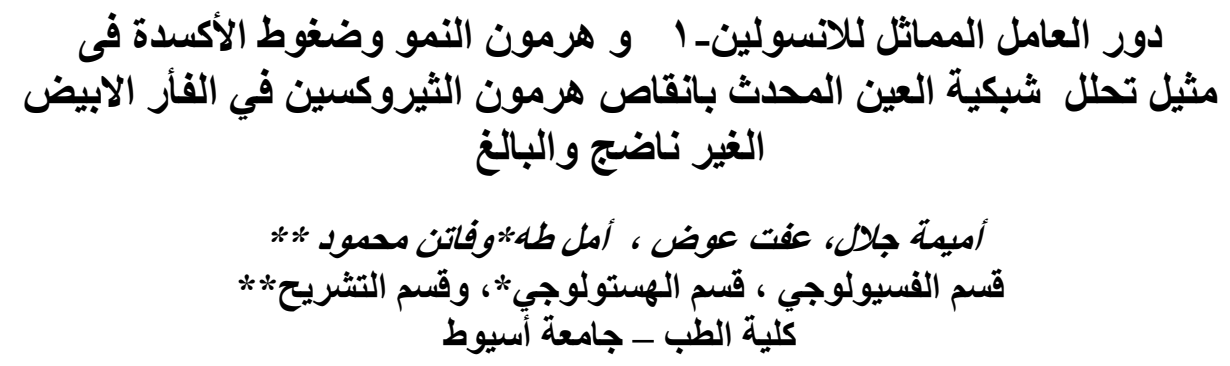

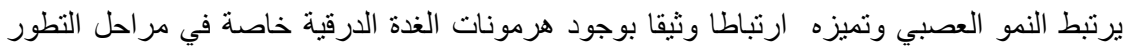

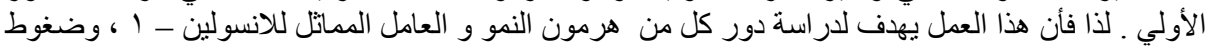

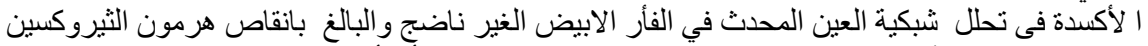

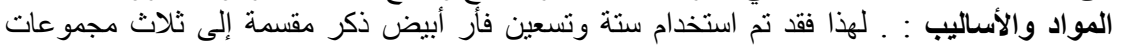

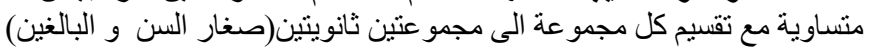

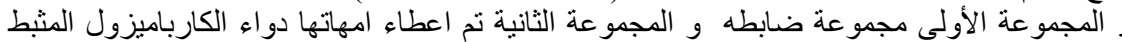

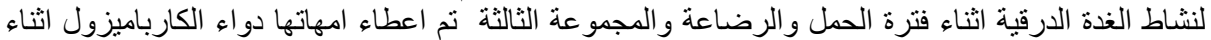

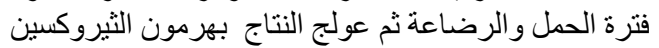

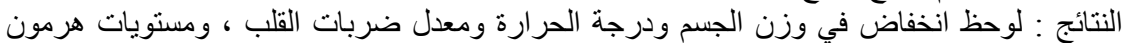

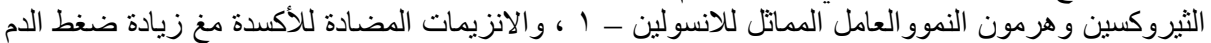

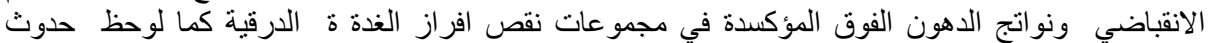

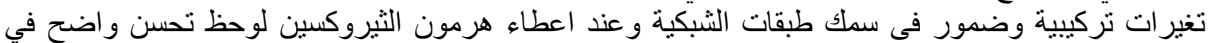

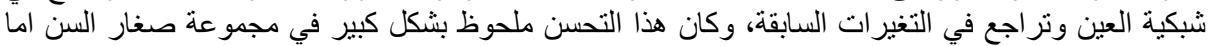

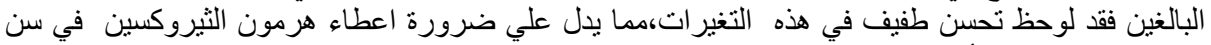
مبكرة للحصول علي أفضل النتائج. 